\title{
PERSPECTIVE \\ Planning for the Post-COVID Syndrome: How Payers Can Mitigate Long-Term Complications of the Pandemic
}

\author{
David H. Jiang, B.A. ${ }^{7} \oplus$ and Rozalina G. McCoy, M.D., M.S. ${ }^{1,2}$ \\ 'Department of Health Sciences Research, Division of Health Care Policy \& Research, Mayo Clinic, Rochester, MN, USA; ${ }^{2}$ Department of Internal \\ Medicine, Division of Community Internal Medicine, Mayo Clinic, Rochester, MN, USA.
}

As the COVID-19 pandemic continues to unfold, payers across the USA have stepped up to alleviate patients' financial burden by waiving cost-sharing for COVID-19 testing and treatment. However, there has been no substantive discussion of potential long-term effects of COVID-19 on patient health or their financial and policy implications. After recovery, patients remain at risk for lung disease, heart disease, frailty, and mental health disorders. There may also be long-term sequelae of adverse events that develop in the course of COVID-19 and its treatment. These complications are likely to place additional medical, psychological, and economic burdens on all patients, with lower-income individuals, the uninsured and underinsured, and individuals experiencing homelessness being most vulnerable. Thus, there needs to be a comprehensive plan for preventing and managing postCOVID-19 complications to quell their clinical, economic, and public health consequences and to support patients experiencing delayed morbidity and disability as a result.

KEY WORDS: COVID-19; access to care; uninsured; underinsured; costsharing.

J Gen Intern Med 35(10):3036-9

DOI: $10.1007 / \mathrm{s} 11606-020-06042-3$

(c) Society of General Internal Medicine 2020

\section{INTRODUCTION}

As the COVID-19 pandemic continues to plague the USA, public and private payers have stepped up to alleviate some of the financial stresses on patients and the health care system. Recognizing that widespread and timely testing is critical to curbing the scope and impact of COVID-19, and cognizant of cost-related barriers to testing that patients are likely to experience, the Families First Coronavirus Response Act (FFCRA), passed on March 18, 2020, mandated group health plans and health insurers offering group or individual health policies to provide testing for COVID-19 without any costsharing by the patient. FFCRA also allocated funding to allow COVID-19 testing to be provided at no cost for those on public health insurance programs, such as Medicare and Medicaid. Medicare and most private insurance companies went further to also waive cost-sharing for the treatment of COVID-19. ${ }^{1}$

Received May 1, 2020

Accepted July 7, 2020

Published online July 22, 2020
However, as most patients with COVID-19 infection ultimately survive, clinicians and policymakers cannot lose sight of the potential long-term consequences of COVID-19 on patient health and economic stability. With 640,198 COVID-19 survivors in the USA as of June 23, 2020, and a total of 2,328,562 known cases to date, ${ }^{2}$ we must anticipate and plan for the personal and financial tolls of near- and long-term sequelae of COVID-19 and its treatments, while simultaneously taking proactive steps to minimize these risks.

\section{POTENTIAL LONG-TERM COMPLICATIONS of COVID-19}

For patients diagnosed with COVID-19, surviving the disease may be just the first battle among many on the long road to recovery. Although there is not yet enough data to definitively establish and characterize a post-COVID-19 syndrome, potential long-term consequences can be inferred from emerging data as well as prior experiences with other serious respiratory illnesses and the broader post-intensive care syndrome (PICS), a constellation of physical, cognitive, and psychological disabilities that can develop in those surviving critical illness. ${ }^{3}$ Patients with severe manifestations of COVID-19 often progress to acute respiratory distress syndrome (ARDS) and require mechanical ventilation. ARDS may cause permanent scarring of the lung tissue, resulting in respiratory problems that persist long after recovery. ${ }^{4}$ Between 33 and $75 \%$ of patients with COVID-19 require mechanical ventilation, often for weeks at a time, ${ }^{5,6}$ and there are significant short- and long-term effects associated with prolonged intubation. Those on ventilators are more prone to respiratory infections, which, in turn, predispose patients to further harm and risk of permanent lung damage. Patients experiencing PICS generally report higher incidences of cognitive and physical dysfunction, which often persist long-term. ${ }^{7}$ PICS can also lead to disability and moderate or severe pain. ${ }^{8}$ Because patients with severe COVID-19 infection frequently require prolonged intensive care unit (ICU) stays, ${ }^{5,6}$ we hypothesize that survivors will be similarly at heightened risk of all these physical and cognitive impairments. This may be further exacerbated by the fact that unlike other patients requiring mechanical ventilation or in the ICU, patients with COVID-19 may not receive the physical and occupational therapy they need to recover due to concerns over spreading the disease or inadequate medical personnel or 
other resources, resulting in even greater likelihood of persistent functional loss and debility.

COVID-19 infection is also associated with high rates of extra-pulmonary complications that may continue to incur morbidity, disability, and delayed mortality in survivors. These include cardiac injury, ${ }^{9-11}$ acute ischemic or hemorrhagic stroke, ${ }^{12}$ neurological deficits, ${ }^{13}$ acute kidney injury, including the need for dialysis, and liver injury. ${ }^{14}$ The thromboembolic complications of COVID-19, such as pulmonary embolism, stroke, and other microinfarctions, can cause a wide range of permanent organ damage. Independent of ARDS, severe pneumonia has been associated with increased risk of incident heart disease both in the immediate aftermath of the infection and in later years. ${ }^{15}$ It is likely that the risk of heart disease in COVID-19 survivors will be even higher, confounded by high rates of underlying cardiovascular disease, hypertension, and diabetes among patients with severe COVID-19 infection and the independent effects of COVID19 on the cardiovascular system.

Even if patients with COVID-19 recover physically, they are vulnerable to long-lasting mental health problems. Longterm psychological distress and post-traumatic stress disorder can develop in more than half of patients who survive critical illness. ${ }^{16}$ While there is no long-term data on the psychological effects of COVID-19 infection and treatment, an earlier study of patients hospitalized for severe acute respiratory syndrome (SARS) found that more than one-third had moderate to severe depression and anxiety 1 year after physical recovery. ${ }^{17}$ The mental health effects of surviving COVID19 may be further compounded by loneliness and isolation, job and economic loss, increased child care and familial responsibilities, and guilt if family members or other contacts contract the virus. Finally, COVID-19 survivors may experience chronic pain, which is commonly reported by ICU survivors, ${ }^{18}$ potentially compounding the epidemic of opioid misuse already affecting many of the same vulnerable populations.

\section{VULNERABLE POPULATIONS}

While nearly all public and private health insurance companies indicated that they would waive cost-sharing for COVID-19 testing and related treatments, it is unclear whether and how these "related treatments" extend to delayed and long-term complications that stem from COVID-19. This ambiguity and potential for substantial out-of-pocket expenditures in the aftermath of COVID-19 recovery are especially burdensome for patients who are uninsured or underinsured. A recent poll has found that $14 \%$ of Americans reported likely forgoing seeking medical care for COVID-19 symptoms due to their inability to pay. ${ }^{19}$ While they may receive treatment for COVID-19 itself at minimal or no cost, they remain liable for cost-sharing expenses associated with the long-term physical and mental health complications they are almost certain to develop. COVID-19 has disproportionately affected lower- income individuals and people of color, ${ }^{20}$ who may not have the financial reserves to meet the demands of their future health needs. Uninsured, lower-income, and minority patients also have higher rates of underlying health conditions and obesity, all of which increase the probability of severe COVID-19 symptoms and, presumably, its long-term complications. ${ }^{21}$ Cost-related barriers to seeking necessary medical care will mean deterioration of health, debility, and potential death that would disproportionately affect those unable to pay. The situation is even more challenging for patients without health coverage. Although the FFCRA covers testing for the uninsured, those individuals still need treatment, which is not covered by the FFCRA. This lack of coverage already places a substantial economic and health burden on the uninsured, making potential long-term complications for these individuals even more devastating. ${ }^{22}$

Underinsured patients, such as those with high deductible health plans (HDHPs), are also vulnerable to high out-ofpocket costs. Over $30 \%$ of individuals in employersponsored health plans, or over 47 million Americans, are currently covered by HDHPs. ${ }^{23-25}$ HDHP enrollees are more likely to forgo preventative care and are less adherent to medications for chronic health conditions. ${ }^{26-30}$ These financial barriers to seeking, obtaining, and adhering to medical care will undoubtedly be exacerbated in the presence of additional health needs that are likely to arise in the aftermath of COVID-19 infection and the financial hardship that many in the USA may experience after a period of unemployment or underemployment.

Undocumented immigrants, people experiencing homelessness, and other marginalized groups may be most likely to see these gaps in health coverage and, thus, forego needed care. ${ }^{31}$ The impact of inadequate health insurance coverage will be felt most strongly in states that did not expand Medicaid coverage and, thus, have the highest rates of the uninsured. ${ }^{32}$ These states already have profound disparities in health outcomes among minority and low-income populations, which will likely become further exacerbated in the aftermath of COVID-19. ${ }^{33,34}$

\section{DISCUSSION AND POLICY IMPLICATIONS}

The fight against COVID-19 will extend beyond the immediate infectious period and efforts to screen for and manage acute disease. The 2,328,562 Americans with confirmed COVID-19, particularly those who have been hospitalized, ${ }^{2}$ will experience some degree of long-term disability and morbidity as a result of their infection. There are likely many others with COVID-19 who have yet to be tested and diagnosed, ${ }^{35-37}$ and the complications they may ultimately develop will manifest themselves in the months and years to come. With over 2.3 million Americans already infected, and millions more likely affected in the future, this will result in substantial burdens to the healthcare system not just now but in the future. 
While it is difficult to predict the nature and scope of longterm medical and financial complications that may arise from COVID-19, past experience provides some forewarning of what they could be. Governments and payers at all levels have responded to the need to resolve short-term health policy issues, including affordability and accessibility of COVID19 testing and treatment, but there is yet to be any serious discussion devoted to the burden of its long-term complications. The lack of these discussions has serious implications that will impact patients, families, the healthcare system, and the overall economy. Vulnerable patients who develop postCOVID syndromes could place additional burdens on community hospitals and emergency rooms during a time when they are already stretched thin and recovering from financial losses sustained during the pandemic. There are already reports of patients being "surprised" with massive medical bills after COVID-19 treatment. ${ }^{38}$ Unable to pay for needed care, patients may resort to bankruptcy or forego needed care, with potentially fatal implications. The disability and morbidity associated with COVID-19 complications, particularly if not treated, can lead to decreased productivity, disability, and leaving the workforce for the long-term.

Even at present, payers can support efforts to reduce the risk of long-term COVID-19 complications. This includes, as examples, access to physical therapy for patients with prolonged hospitalization, mechanical ventilation, or ICU care; mental health services for those at increased risk of depression, anxiety, or post-traumatic stress; and timely treatment of complications that may develop in the course of managing COVID19. These services should be offered to the broadest range of people possible, and at minimal cost, to ensure that the most vulnerable are not excluded. At the very least, COVID-19 and its complications should not be considered as a "pre-existing condition," whose presence may someday make it more difficult, if not impossible, to obtain health coverage if protections enacted as part of the Affordable Care Act are reversed.

Substantive policy changes at various levels can also help alleviate the potential burden of post-COVID syndrome. State governments and departments of health can make it easier for survivors to receive physical therapy and physical and mental health evaluations by allowing patients to access these services at no cost within the first year of diagnosis. The $\$ 2$ trillion Coronavirus Aid, Relief, and Economic Security (CARES) Act passed by Congress allocated $\$ 100$ billion for hospitals to deliver acute care, with no funds to prevent, detect, or mitigate post-COVID19 syndromes. ${ }^{39}$ We recommend that Congress enact additional legislation to direct national resources to clinics and community centers for mental health professionals, physical therapists, primary care clinicians, and others to care for millions of Americans with long-term COVID-19related needs. Similarly, employment support and retraining programs may be needed to help patients with new disabilities identify alternative employment opportunities that accommodate their needs.
More research and education are needed to better understand, characterize, and recognize the post-COVID syndrome in diverse settings and populations. This includes developing screening guidelines and continuing medication education courses that would raise awareness among clinicians and promote evidence-based management strategies. Survivorship clinics, similar to models increasingly developed for cancer survivors, may be an efficient way to deliver multidisciplinary care. Finally, clinicians and public health professionals should make patients aware of the potential long-term complications of COVID-19, including suspected and asymptomatic cases, and encourage them to seek medical and mental health care for any conditions they may develop.

The COVID-19 pandemic is far from over, and the Centers for Disease Control and Prevention has cautioned about a likely resurgence of the disease in the fall. While patients, clinicians, and a vast army of essential workers continue to battle COVID-19 on the front lines, policymakers and payers must look toward the future. There needs to be a comprehensive plan for preventing and managing post-COVID-19 complications and supporting patients and families experiencing delayed morbidity and disability as a result. Health protection and policies should extend beyond the present and ensure that COVID-19 kills as few people as possible now and the future.

Corresponding Author: David H. Jiang, B.A.; Department of Health Sciences Research, Division of Health Care Policy \& Research, Mayo Clinic, Rochester, MN, USA (e-mail: jiang.david@mayo.edu).

\section{Compliance with Ethical Standards:}

Conflict of Interest: The authors have no conflicts of interest to disclose. Dr. McCoy is supported by the National Institute of Diabetes and Digestive and Kidney Diseases of the National Institute of Health (K23DK114497). In the past 36 months, she has also received support from the Mayo Clinic Robert D. and Patricia E. Kern Center for the Science of Health Care Delivery and from AARP ${ }^{\circledR}$ (Quality Measure Innovation Grant).

\section{REFERENCES}

1. Health Insurance Providers Respond to Coronavirus (COVID-19). America's Health Insurance Plans, 2020. (Accessed April 21, 2020, 2020, at https://www.ahip.org/health-insurance-providers-respond-tocoronavirus-covid-19/?mod=article_inline\#U.)

2. Dong $\mathbf{E}, \mathbf{D u} \mathbf{H}$, Gardner $\mathbf{L}$. An interactive web-based dashboard to track COVID-19 in real time. Lancet Infect Dis. 2020.

3. Ohtake PJ, Lee AC, Scott JC, et al. Physical Impairments Associated With Post-Intensive Care Syndrome: Systematic Review Based on the World Health Organization's International Classification of Functioning, Disability and Health Framework. Phys Ther. 2018;98:631-45.

4. Thompson BT, Chambers RC, Liu KD. Acute Respiratory Distress Syndrome. N Engl J Med. 2017;377:562-72.

5. Goyal P, Choi JJ, Pinheiro LC, et al. Clinical Characteristics of Covid-19 in New York City. N Engl J Med. 2020.

6. Bhatraju PK, Ghassemieh BJ, Nichols M, et al. Covid-19 in Critically Ill Patients in the Seattle Region - Case Series. N Engl J Med. 2020.

7. Pandharipande PP, Girard TD, Jackson JC, et al. Long-term cognitive impairment after critical illness. N Engl J Med. 2013;369:1306-16.

8. Griffiths J, Hatch RA, Bishop J, et al. An exploration of social and economic outcome and associated health-related quality of life after critical illness in general intensive care unit survivors: a 12-month followup study. Crit Care. 2013;17:R100. 
9. Huang $\mathbf{C}$, Wang $\mathbf{Y}$, Li X $\mathbf{X}$, et al. Clinical features of patients infected with 2019 novel coronavirus in Wuhan, China. Lancet. 2020;395:497-506.

10. Shi S, Gin M, Shen B, et al. Association of Cardiac Injury With Mortality in Hospitalized Patients With COVID-19 in Wuhan, China. JAMA Cardiol. 2020 .

11. Bangalore S, Sharma A, Slotwiner A, et al. ST-Segment Elevation in Patients with Covid-19 - A Case Series. N Engl J Med. 2020.

12. Mao L, Jin H, Wang $\mathbf{M}$, et al. Neurologic Manifestations of Hospitalized Patients With Coronavirus Disease 2019 in Wuhan, China. JAMA Neurol. 2020.

13. Helms J, Kremer S, Merdji H, et al. Neurologic Features in Severe SARS-CoV-2 Infection. N Engl J Med. 2020.

14. Zhang C, Shi L, Wang F-S. Liver injury in COVID-19: management and challenges. Lancet Gastroenterol Hepatol. 2020;5:428-30.

15. Corrales-Medina VF, Alvarez KN, Weissfeld LA, et al. Association between hospitalization for pneumonia and subsequent risk of cardiovascular disease. JAMA. 2015;313:264-74.

16. Hatch R, Young D, Barber V, Griffiths J, Harrison DA, Watkinson P. Anxiety, Depression and Post Traumatic Stress Disorder after critical illness: a UK-wide prospective cohort study. Crit Care. 2018;22:310.

17. Lee AM, Wong JG, McAlonan GM, et al. Stress and Psychological Distress among SARS Survivors 1 Year after the Outbreak. Can J Psychiatry. 2007;52:233-40.

18. Devine H, Quasim T, McPeake J, Shaw M, McCallum L, Mactavish P Chronic pain in intensive care unit survivors: incidence, characteristic and side-effects up to one-year post-discharge. J Rehabil Med. 2019;51:451-5

19. In U.S., 14\% With Likely COVID-19 to Avoid Care Due to Cost. Gallup, 2020. (Accessed April 29, 2020, 2020, at https://news.gallup.com/poll/ 309224/avoid-care-likely-covid-due-cost.aspx.)

20. Artiga S, Orgera K, Pham O, Corallo B. Growing Data Underscore that Communities of Color are Being Harder Hit by COVID-19: The Kaiser Family Foundation; 2020.

21. Koma W, Neuman T, Claxton G, Rae M, Kates J, Michaud J. How Many Adults Are at Risk of Serious Illness If Infected with Coronavirus? Updated Data: Kaiser Family Foundation; 2020.

22. Turret E, Gluck AR, Beckman AL, et al. The Families First Coronavirus Response Act Is Necessary But Not Sufficient - Here's What Congress Should Do Next. Health Affairs Blog. 2020.

23. Claxton G, Rae M, Damico A, Young G, McDermott D. Employer Health Benefits: 2019 Annual Survey: Henry J. Kaiser Family Foundation: 2019.

24. Health Insurance Coverage of the Total Population. In: Foundation KF, ed. State Health Facts. Online; 2018.
25. According to the Kaiser Family Foundation, there were $157,299,500$ Americans who are covered by employer-sponsered health plans. Of which $30 \%$ were HDHP.

26. Agarwal R, Mazurenko O, Menachemi N. High-Deductible Health Plan Reduce Health Care Cost And Utilization, Including Use Of Needed Preventive Services. Health Aff (Millwood). 2017;36:1762-8.

27. Wharam JF, Zhang F, Lu CY, et al. Breast Cancer Diagnosis and Treatment After High-Deductible Insurance Enrollment. J Clin Oncol. 2018;36:1121-7.

28. Wharam JF, Galbraith AA, Kleinman KP, Soumerai SB, Ross-Degnan D, Landon BE. Cancer screening before and after switching to a highdeductible health plan. Ann Intern Med. 2008;148:647-55.

29. Pollack CE, Mallya G, Polsky D. The impact of consumer-directed health plans and patient socioeconomic status on physician recommendations for colorectal cancer screening. J Gen Intern Med 2008;23:1595-601

30. Fendrick AM, Buxbaum JD, Tang Y, et al. Association Between Switching to a High-Deductible Health Plan and Discontinuation of Type 2 Diabetes Treatment. JAMA Netw. 2019;2:e1914372.

31. Page KR, Venkataramani M, Beyrer C, Polk S. Undocumented U.S. Immigrants and Covid-19. N Engl J Med. 2020.

32. Garfield R, Orgera K, Damico A. The Coverage Gap: Uninsured Poor Adults in States that Do Not Expand Medicaid: Kaiser Family Foundation; 2020.

33. Lyon SM, Douglas IS, Cooke CR. Medicaid expansion under the Affordable Care Act. Implications for insurance-related disparities in pulmonary, critical care, and sleep. Ann Am Thorac Soc. 2014;11:661-7.

34. Guth M, Garfield R, Rudowitz R. The Effects of Medicaid Expansion under the ACA: Updated Findings from a Literature Review: Kaiser Family Foundation; 2020.

35. Koerth M, Bronner L, Mithani J. Why It's So Freaking Hard To Make A Good COVID-19 Model. FiveThirtyEight. 2020;31:2020.

36. Harmon A. Why We Don't Know the True Death Rate for COVID-19. The New York Times. 2020.

37. Prakash N, Hall E. Doctors and Nurses Say More People Are Dying Of COVID-19 In The US Than We Know. BuzzFeed News. 2020;25:2020.

38. Westneat D. Coronavirus survival comes with \$1.1 million, 181-page price tag. The Seattle Times 2020 June 12, 2020.

39. Coronavirus Aid, Relief, and Economic Security Act. United States; 2020.

Publisher's Note Springer Nature remains neutral with regard to jurisdictional claims in published maps and institutional affiliations. 